\title{
Fluorescence Polarization Binding Assay for Aspergillus fumigatus Virulence Factor UDP-Galactopyranose Mutase
}

\author{
Jun Qi, ${ }^{1,2}$ Michelle Oppenheimer, ${ }^{1,2}$ and Pablo Sobrado ${ }^{1,2,3}$ \\ ${ }^{1}$ Department of Biochemistry, Virginia Tech, Blacksburg, VA 26061, USA \\ ${ }^{2}$ Enzyme Research and Drug Discovery Laboratory, Virginia Tech, Blacksburg, VA 26061, USA
}

${ }^{3}$ Fralin Life Science Institute, Virginia Tech, Blacksburg, VA 26061, USA

Correspondence should be addressed to Pablo Sobrado, psobrado@vt.edu

Received 2 April 2011; Accepted 20 May 2011

Academic Editor: Qi-Zhuang Ye

Copyright $\odot 2011$ Jun Qi et al. This is an open access article distributed under the Creative Commons Attribution License, which permits unrestricted use, distribution, and reproduction in any medium, provided the original work is properly cited.

\begin{abstract}
Aspergillus fumigatus is an opportunistic human pathogenic fungus responsible for deadly lung infections in immunocompromised individuals. Galactofuranose (Galf) residues are essential components of the cell wall and play an important role in A. fumigatus virulence. The flavoenzyme UDP-galactopyranose mutase (UGM) catalyzes the isomerization of UDP-galactopyranose to UDPgalactofuranose, the biosynthetic precursor of Galf. Thus, inhibitors of UGM that block the biosynthesis of Gal $f$ can lead to novel chemotherapeutics for treating A. fumigatus-related diseases. Here, we describe the synthesis of fluorescently labeled UDP analogs and the development of a fluorescence polarization (FP) binding assay for A. fumigatus UGM (AfUGM). High-affinity binding to Af UGM was only obtained with the chromophore TAMRA, linked to UDP by either 2 or 6 carbons with $K_{d}$ values of $2.6 \pm 0.2 \mu \mathrm{M}$ and $3.0 \pm 0.7 \mu \mathrm{M}$, respectively. These values were $\sim 6$ times lower than when UDP was linked to fluorescein. The FP assay was validated against several known ligands and displayed an excellent $Z^{\prime}$ factor $(0.79 \pm 0.02)$ and good tolerance to dimethyl sulfoxide.
\end{abstract}

\section{Introduction}

Aspergillus fumigatus is an opportunistic human pathogen responsible for diseases such as allergic reactions and lung infections, including bronchopulmonary aspergillosis (ABPA) and invasive pulmonary aspergillosis (IPA) $[1,2]$. This fungus is a significant health threat to immunocompromised patients, such as organ transplant recipients and people with AIDS or leukemia $[3,4]$. It has been reported that IPA infections are typically accompanied by a mortality rate of 50-70\% [5]. Thus, identification of novel and effective drug targets is essential in the fight against fungal infections.

Recently, the biosynthetic pathway of galactofuranose (Galf), the 5-membered ring form of galactose, has been described in A. fumigatus. Galf is a component of the cell wall of A. fumigatus and plays an important role in virulence [68]. In A. fumigatus, Galf was first identified as a component of galactomannan by immunodetection in IPA patients [9]. Later, it was found that Galf is also a major component of saccharide structures in membrane lipids and glycosyl phosphoinositol (GPI-)anchored lipophospholipids [10,11].
UDP-galactopyranose mutase (UGM) is a flavoenzyme that catalyzes the conversion of UDP-galactopyranose (UDPGal $p$ ) to UDP-galactofuranose (UDP-Galf, Figure 1), the biosynthetic precursor of Galf $[7,12]$. Deletion of the $A$. fumigatus UGM (AfUGM) gene results in mutant fungi with attenuated virulence, a decrease in cell wall thickness, and an increase in the sensitivity to antifungal agents $[8,13]$. Moreover, Galf is absent in humans [12]. Thus, inhibitors of AfUGM that block the biosynthesis of Galf represent attractive drug targets for the identification of novel therapeutics against $A$. fumigatus.

Here, we describe the development of a fluorescence polarization (FP) binding assay to identify specific AfUGM inhibitors. Four fluorescently labeled UDP derivatives including two known UDP-fluorescein analogs (1 and 2, Figure 2) and two novel UDP-TAMRA analogs ( 3 and $\mathbf{4}$, Figure 2) were synthesized to be used as fluorescent probes in the FP assay. Their concentrations were optimized to obtain a stable FP signal with minimal standard deviation, and their $K_{d}$ values were determined by measuring the anisotropy changes as a function of AfUGM concentration. 


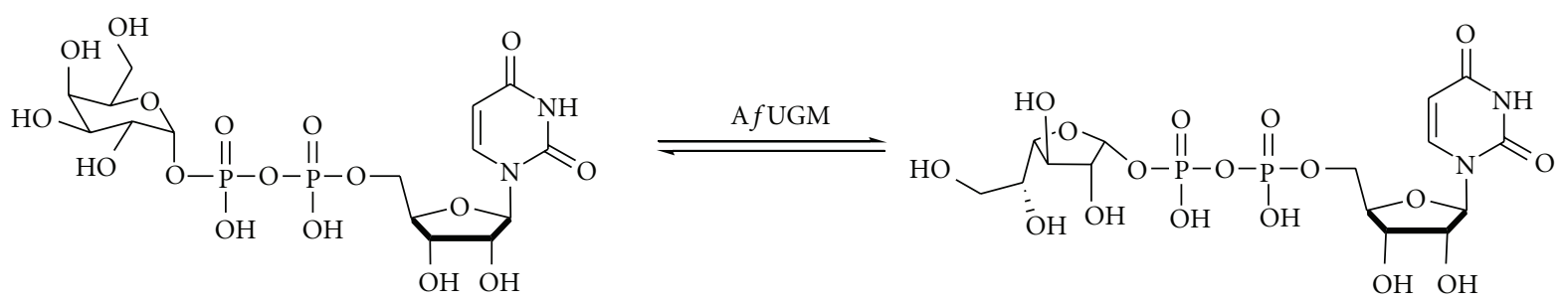

UDP-Galp

UDP-Gal $f$

FIGURE 1: Reaction catalyzed by AfUGM.

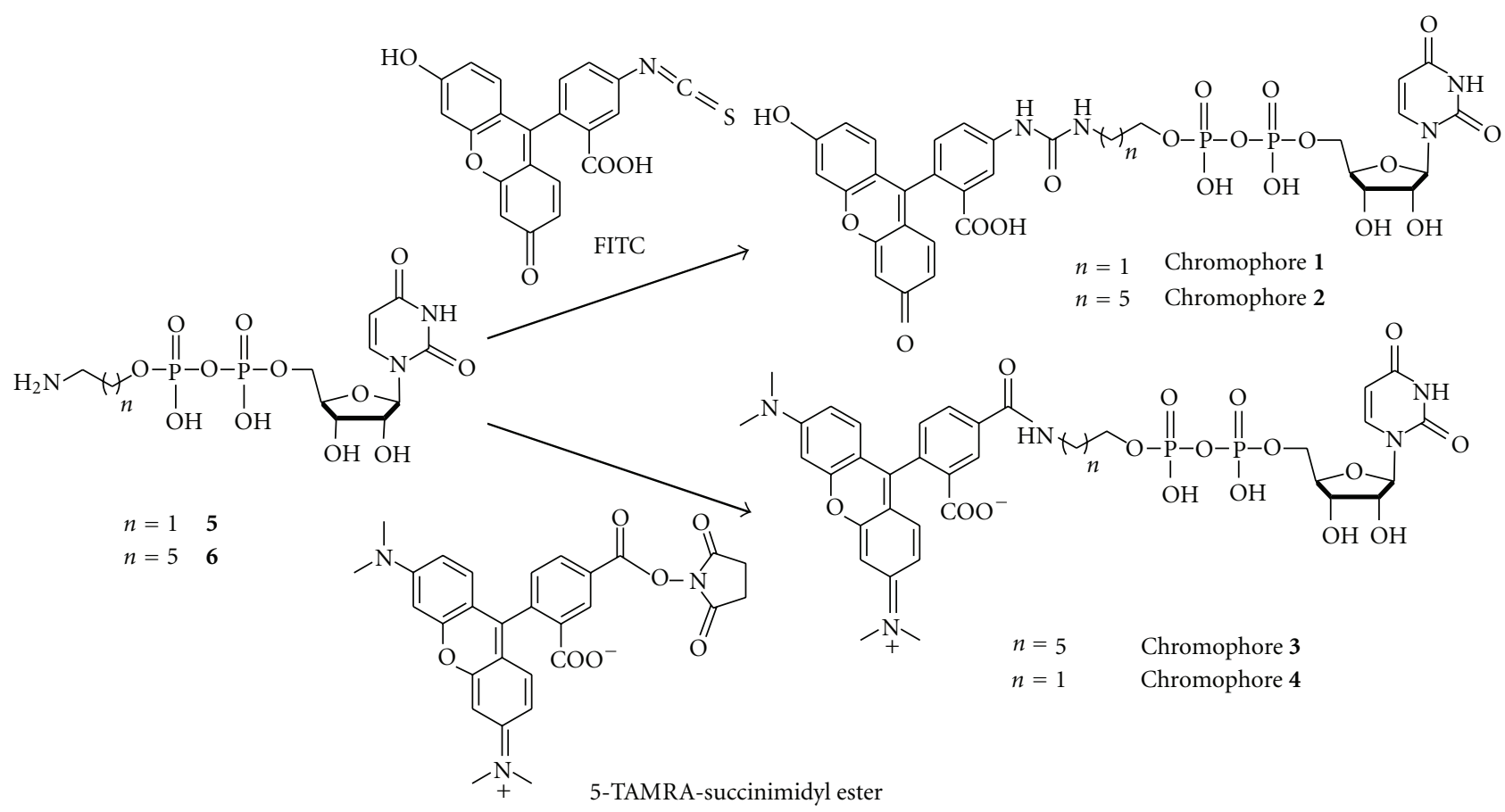

FIgURE 2: Synthetic scheme of the chromophores used as ligands to AfUGM for application in FP assays.

We found that the UDP-TAMRA analogs bind to AfUGM 6-fold tighter than the UDP-fluorescein analogs, suggesting that UDP-TAMRA analogs are better fluorescent probes for this enzyme. UDP-TAMRA probes could be competed out by UDP, a known ligand of UGMs, and the $K_{d}$ value of UDP was in good agreement with the value determined previously in a fluorescence assay [7]. Furthermore, the FP assay was validated using several known ligands and displayed an excellent $Z^{\prime}$ factor $(0.79 \pm 0.02)$ and good tolerance to DMSO. Therefore, this fast convenient one-step FP assay is suitable for a high-throughput screening to identify AfUGM inhibitors.

\section{Materials and Methods}

2.1. Materials. All chemicals were obtained from commercial sources and were used without further purification. Anhydrous reactions were performed under argon. All solvents were either reagent grade or HPLC grade. NMR spectral data were obtained using a JEOL Eclipse spectrometer at $500 \mathrm{MHz}$, or a Varian Inova spectrometer at $400 \mathrm{MHz}$.
Chemical shifts were reported as $\delta$-values relative to known solvent residue peaks. High-resolution mass spectra (HRMS) were obtained in the Mass Spec Incubator, Department of Biochemistry, Virginia Tech. High-performance liquid chromatography (HPLC) was performed on a C18 reverse phase column (Phenomenex Luna C18 column, $250 \times$ $21.20 \mathrm{~mm}, 5$ microns) using water and acetonitrile as the elution solvents. All compounds were more than $95 \%$ pure as judged by HPLC and ${ }^{1} \mathrm{H}$ NMR.

2.2. Protein Expression and Purification. AfUGM and $M t$ UGM were expressed and purified with the same protocol as described by Oppenheimer et al. [7]. A large quantity of highly pure AfUGM was obtained, which was confirmed by UV-visible spectrophotometry and SDS-PAGE (see Figure S1 Supplementary Material available online at doi:10.4061/2011/513905).

2.3. Synthesis of UDP-Fluorescein Chromophore 1 and 2. The synthesis of chromophore 1 was accomplished by reacting 


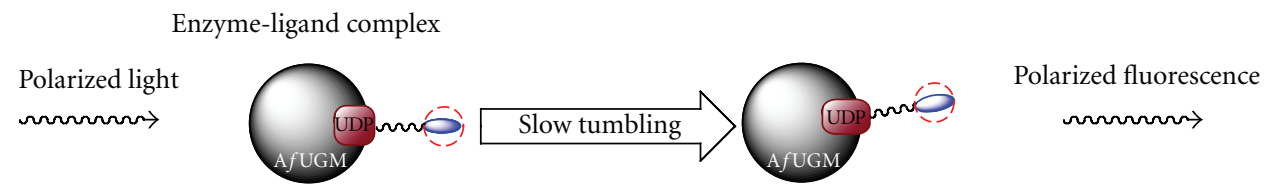

(a)

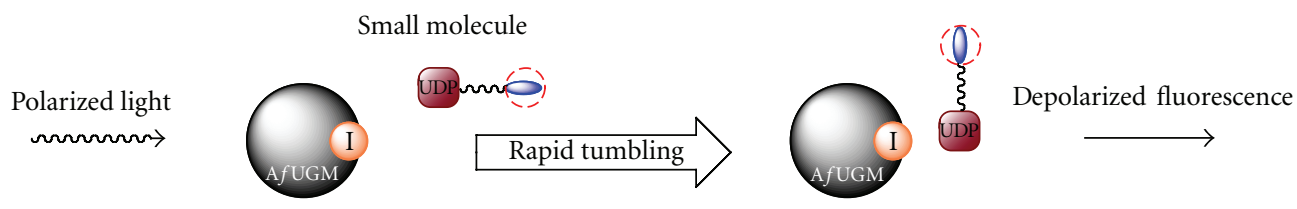

$$
\begin{aligned}
& \text { (9) = Fluorophore (fluorescein or TAMRA) } \\
& \text { (I) = Inhibitor }
\end{aligned}
$$

(b)

FIGURe 3: FP assay design. (a) Binding of the FP probe to AfUGM leads to polarized fluorescence. (b) Displacement of the FP probe from AfUGM by inhibitor results in depolarized fluorescence.

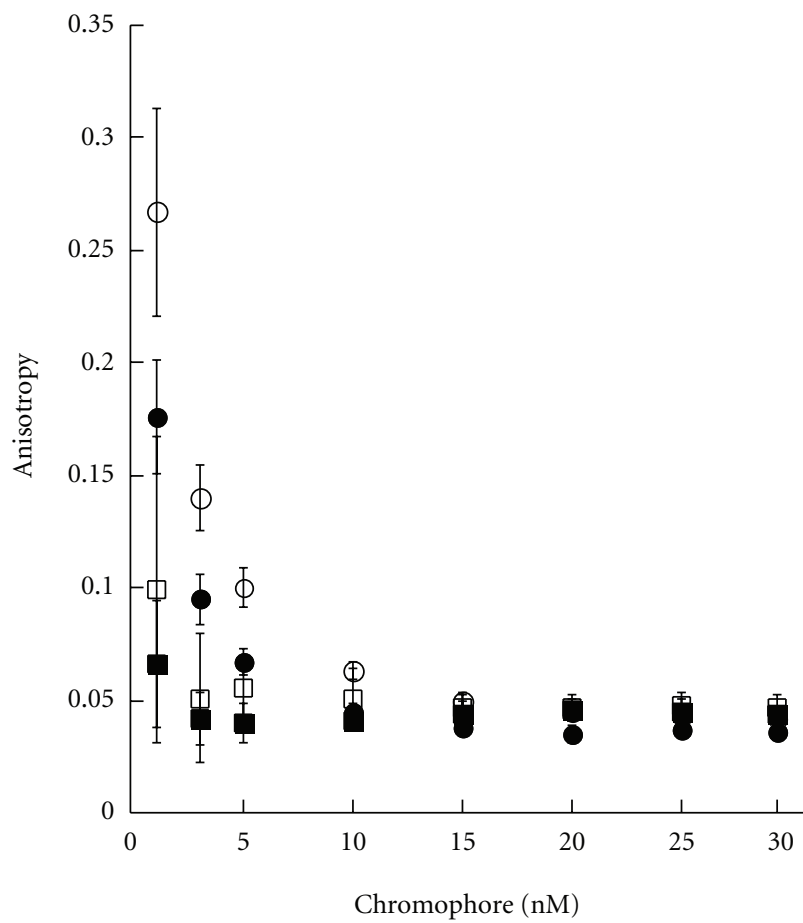

FIGURE 4: Determination of optimal concentration of fluorescent probe for FP binding assay. Conditions are described in Material and Methods sections. Chromophore $1(\bigcirc), 2(\mathbf{0})$ (excitation at

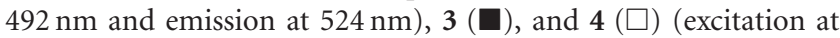
$544 \mathrm{~nm}$ and emission at $584 \mathrm{~nm}$ ).

$4 \mathrm{mg}$ of compound 5, which was synthesized following a previously published procedure [15], with $6 \mathrm{mg}$ of fluorescein5-isothiocyanate (FITC) in $0.1 \mathrm{M} \mathrm{pH} 9.0 \mathrm{NaHCO}_{3}$ buffer $(50 \mu \mathrm{L})$ and DMF $(100 \mu \mathrm{L})$ (Figure 2$)$. After stirring at room temperature for 2 hours, the yellow solution was concentrated and loaded onto a preparative silica gel TLC plate. The isolated crude product was dissolved in water, injected onto reverse-phase HPLC (Phenomenex Luna C18 column, $250 \times 21.20 \mathrm{~mm}, 5$ microns), and purified at a flow rate of $5.0 \mathrm{~mL} / \mathrm{min}$ with linear gradient elution of $5 \%$ to $95 \%$ acetonitrile in $\mathrm{H}_{2} \mathrm{O}$ over $20 \mathrm{~min}$ to afford chromophore 1 (4 mg, 52\%). ${ }^{1} \mathrm{H}$ NMR (500 MHz, $6: 1 \mathrm{D}_{2} \mathrm{O}: d_{7}$-DMF): $\delta 7.96$ $(\mathrm{d}, J=8.2,1 \mathrm{H}), 7.78(\mathrm{~s}, 1 \mathrm{H}), 7.70(\mathrm{~d}, J=8.1,1 \mathrm{H}), 7.30(\mathrm{dd}, J$ $=8.2,1.5,1 \mathrm{H}), 7.27-7.27(\mathrm{~m}, 2 \mathrm{H})(\mathrm{t}, J=8.7,2 \mathrm{H}), 6.65-6.61$ (m, 2H), 6.61-6.58 (m, 2H), $5.91(\mathrm{~s}, 1 \mathrm{H}), 5.91(\mathrm{~s}, 1 \mathrm{H}), 4.36-$ $4.30(\mathrm{~m}, 2 \mathrm{H}), 4.24-4.21(\mathrm{~m}, 3 \mathrm{H}), 4.19-4.16(\mathrm{~m}, 2 \mathrm{H}), 3.88(\mathrm{~s}$, $2 \mathrm{H})$; HRMS (MALDI) calcd for $\mathrm{C}_{32} \mathrm{H}_{29} \mathrm{~N}_{4} \mathrm{O}_{17} \mathrm{P}_{2} \mathrm{~S}(\mathrm{M}-\mathrm{H})^{-}$: 835.0729, found 835.0759 (Figure S2).

Chromophore $2(7.1 \mathrm{mg}, 55 \%)$ was synthesized from the reaction of compound 6 and FITC by the same procedure as above (Figure 2 ) and was purified by preparative TLC and reverse-phase HPLC (Phenomenex Luna C18 column, 250 $\times 21.20 \mathrm{~mm}, 5 \mathrm{micron}) .{ }^{1} \mathrm{H}$ NMR $\left(500 \mathrm{MHz}, 6: 1 \mathrm{D}_{2} \mathrm{O}: d_{7^{-}}\right.$ $\mathrm{DMF}): \delta 8.00(\mathrm{~d}, J=8.0,1 \mathrm{H}), 7.73(\mathrm{~s}, 1 \mathrm{H}), 7.61(\mathrm{~d}, J=8.3$, $1 \mathrm{H}), 7.31(\mathrm{~d}, J=8.3,1 \mathrm{H}), 7.27-7.27(\mathrm{~m}, 2 \mathrm{H}), 6.66-6.60(\mathrm{~m}$, $4 \mathrm{H}), 5.96(\mathrm{~s}, 1 \mathrm{H}), 4.38-4.34(\mathrm{~m}, 2 \mathrm{H}), 4.27-4.23(\mathrm{~m}, 2 \mathrm{H})$, 4.23-4.18 (m, 2H), 3.97-3.92 (m, 2H), 3.58 (s, 1H), 1.66$1.61(\mathrm{~m}, 4 \mathrm{H}), 1.42-1.36(\mathrm{~m}, 4 \mathrm{H})$; HRMS (MALDI) calcd for $\mathrm{C}_{36} \mathrm{H}_{37} \mathrm{~N}_{4} \mathrm{O}_{17} \mathrm{P}_{2} \mathrm{~S}(\mathrm{M}-\mathrm{H})^{-}$: 891.1350, found 891.1348 (Figure S3).

2.4. Synthesis of UDP-TAMRA Chromophore 3 and 4. The synthesis of chromophore 3 was accomplished by a reaction of $4 \mathrm{mg}$ of compound $\mathbf{6}$, which was synthesized following a previously published procedure [15], with $0.8 \mathrm{mg}$ of 5-carboxytetramethylrhodamine, succinimidyl ester (5TAMRA, SE) in $0.1 \mathrm{M} \mathrm{pH} 8.3 \mathrm{NaHCO}_{3}$ buffer $(50 \mu \mathrm{L})$ and DMF $(50 \mu \mathrm{L})$ (Figure 2). After stirring at room temperature for 2 hours, the pink solution was concentrated and loaded onto a preparative TLC plate. The isolated crude product was 


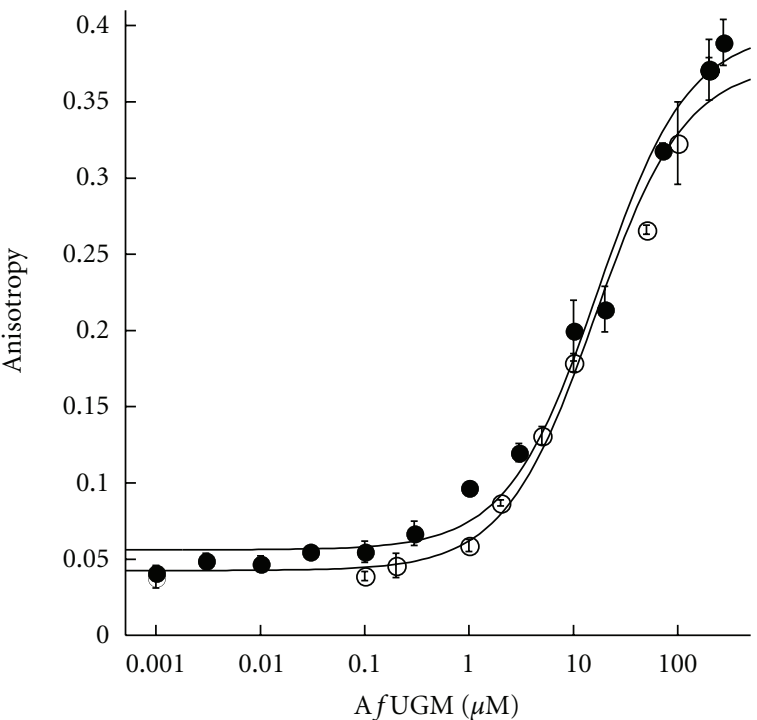

(a)

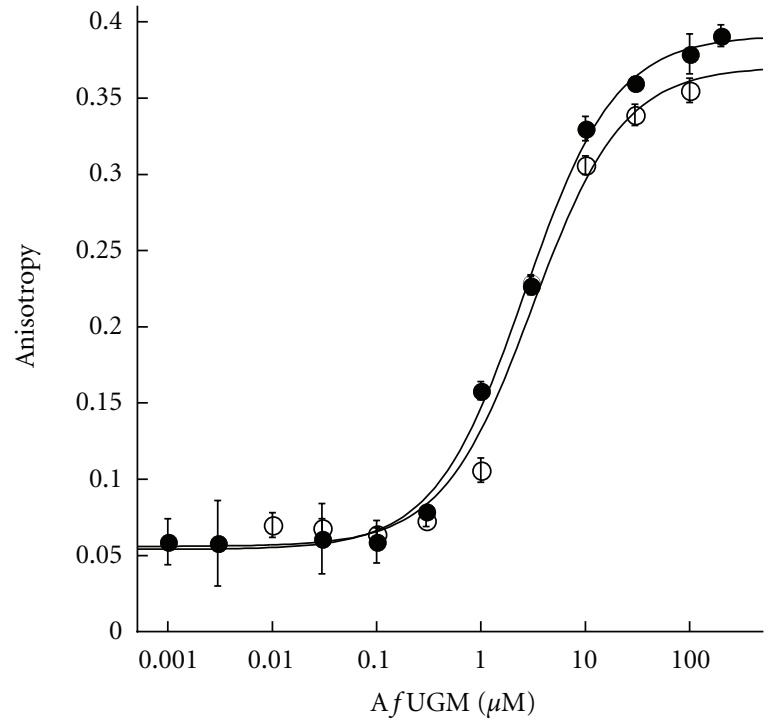

(b)

FIGURE 5: FP binding assay to determine $K_{d}$ of the chromophores. (a) Chromophores $\mathbf{1}(\bigcirc)$ ) and $2(\mathbf{)})$ (excitation at $492 \mathrm{~nm}$ and emission at $524 \mathrm{~nm}$ ). (b) Chromophores $3(\bullet)$ and $4(\bigcirc)$ (excitation at $544 \mathrm{~nm}$ and emission at $584 \mathrm{~nm})$.

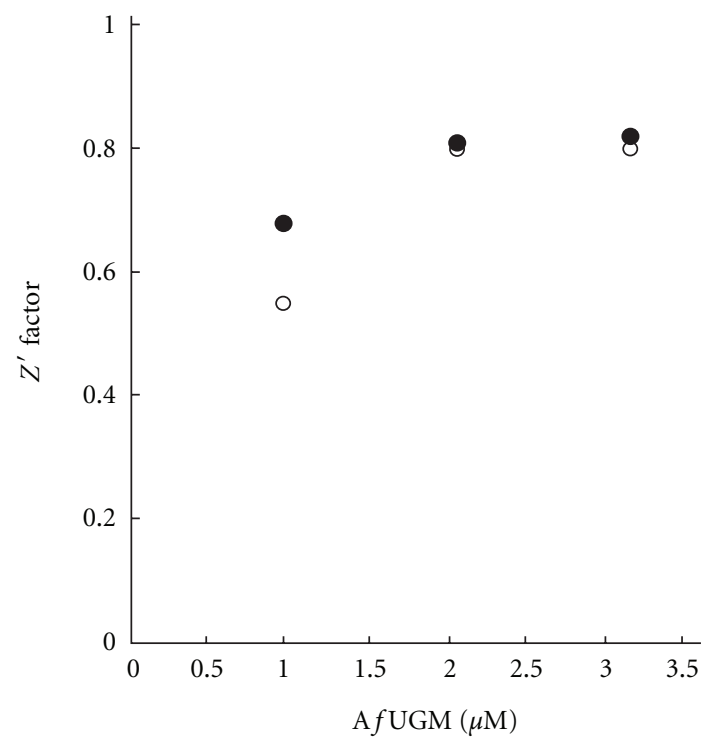

FIGURE 6: Determination of optimal AfUGM concentration to use in the FP assay with chromophore $3(\bullet)$ and chromophore $4(\bigcirc)$.

dissolved in water, injected onto reverse-phase HPLC (Phenomenex Luna C18 column, $250 \times 21.20 \mathrm{~mm}, 5$ microns), and purified at a flow rate of $5.0 \mathrm{~mL} / \mathrm{min}$ with linear gradient elution of $5 \%$ to $95 \%$ acetonitrile in $\mathrm{H}_{2} \mathrm{O}$ over $20 \mathrm{~min}$ to afford chromophore 3 (1.1 mg, 80\%). ${ }^{1} \mathrm{H}$ NMR $(500 \mathrm{MHz}$, $\left.\mathrm{D}_{2} \mathrm{O}\right) \delta 8.22(\mathrm{~s}, 1 \mathrm{H}), 8.08(\mathrm{~d}, J=7.7,1 \mathrm{H}), 7.89(\mathrm{~d}, J=7.3$, $1 \mathrm{H}), 7.60(\mathrm{~d}, J=8.8,1 \mathrm{H}), 7.28-7.22(\mathrm{~m}, 1 \mathrm{H}), 6.91-6.88(\mathrm{~m}$, $2 \mathrm{H}), 6.61(\mathrm{~s}, 1 \mathrm{H}), 6.59(\mathrm{~s}, 1 \mathrm{H}), 5.89-5.83(\mathrm{~m}, 2 \mathrm{H}), 4.35-$ $4.31(\mathrm{~m}, 1 \mathrm{H}), 4.30-4.26(\mathrm{~m}, 1 \mathrm{H}), 4.18-4.15(\mathrm{~m}, 3 \mathrm{H}), 4.00$ $(\mathrm{dd}, J=13.3,6.4,2 \mathrm{H}), 3.49(\mathrm{t}, J=6.8,2 \mathrm{H}), 3.19(\mathrm{~s}, 3 \mathrm{H})$, $3.18(\mathrm{~s}, 3 \mathrm{H}), 1.75-1.67(\mathrm{~m}, 4 \mathrm{H}), 1.51-1.45(\mathrm{~m}, 4 \mathrm{H}), 1.34(\mathrm{~s}$,
$3 \mathrm{H}), 1.32(\mathrm{~s}, 3 \mathrm{H})$; HRMS (MALDI) calcd for $\mathrm{C}_{40} \mathrm{H}_{46} \mathrm{~N}_{5} \mathrm{O}_{16} \mathrm{P}_{2}$ $(\mathrm{M}-\mathrm{H})^{-}$: 914.2415, found 914.2431 (Figure S4). The above synthetic approach was also used to synthesize and purify chromophore 4 (1.5 mg, 77\%). HRMS (MALDI) calcd for $\mathrm{C}_{36} \mathrm{H}_{38} \mathrm{~N}_{5} \mathrm{O}_{16} \mathrm{P}_{2}(\mathrm{M}-\mathrm{H})^{-}:$: 858.1789, found 858.1851 (Figure S5).

2.5. Optimization of Chromophore Concentration. Solutions containing various concentrations of chromophore in $0.05 \mathrm{M}$ sodium phosphate buffer ( $\mathrm{pH}$ 7.0) were added to 12 wells in a 96-well half area black bottom plate (Corning) with final volumes of $25 \mu \mathrm{L}$. FP was analyzed by a SpectraMax M5 plate reader (Molecular Devices). The parallel fluorescence emission $\left(\mathrm{F}_{=}\right)$and perpendicular fluorescence emission $\left(\mathrm{F}_{\perp}\right)$ at $524 \mathrm{~nm}$ (for compounds 1 and 2, excitation at $492 \mathrm{~nm}$ ) or at $584 \mathrm{~nm}$ (for compounds 3 and 4, excitation at $544 \mathrm{~nm}$ ) were measured by a SpectraMax M5 plate reader (Molecular Devices), and the anisotropy ( $r$ ) was calculated using (1), the minimal concentration at which stable FP signals with minimal standard deviations were chosen as the optimal concentration for the chromophore.

$$
\begin{aligned}
r= & \frac{F_{=}-G \cdot F_{\perp}}{F_{=}+2 G \cdot F_{\perp}} \\
y= & m_{1}+\left(m_{2}-m_{1}\right) \\
& \times \frac{\left(x+C_{t}+m_{3}\right)-\sqrt{\left(x+C_{t}+m_{3}\right)^{2}-4 x C_{t}}}{2 C_{t}}
\end{aligned}
$$

2.6. FP Binding Assay to Determine the Chromophore Binding Affinities. Solutions containing serially diluted AfUGM and $15 \mathrm{nM}$ of chromophore in $0.05 \mathrm{M}$ sodium phosphate buffer ( $\mathrm{pH}$ 7.0) were incubated at room temperature for 5 minutes. 


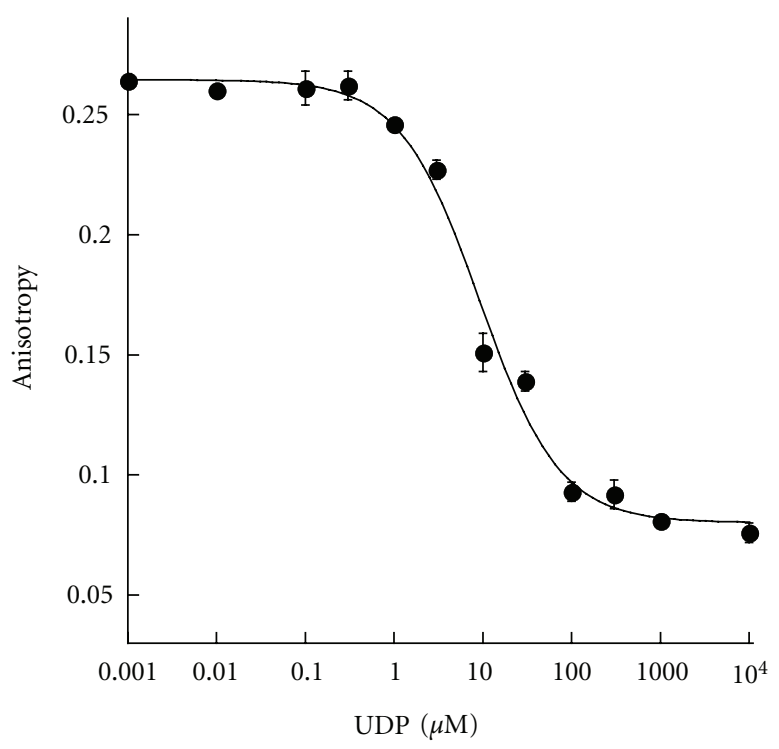

(a)

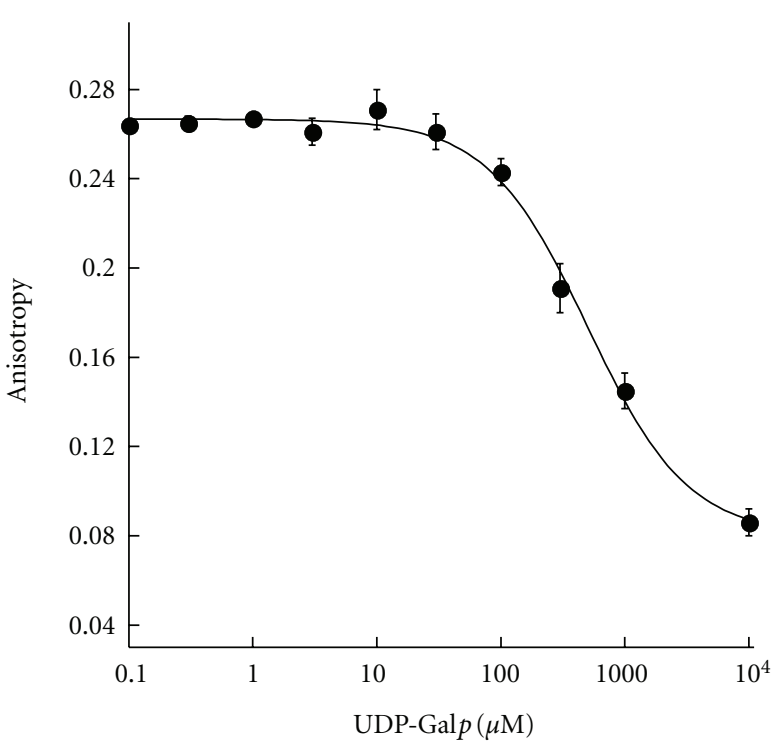

(b)

FIgURE 7: FP competitive binding assay with UDP (a) and UDP-Galp (b).<smiles>O=C(Nc1ccccc1C(=O)O)c1ccc2c(c1)C(=O)N(c1ccc(Br)cc1)C2=O</smiles>

2-(2-(4-bromophenyI)-1, 3-dioxoisoindoline5 -carboxamido) benzoic acid

(7)

(a)<smiles>O=C1N/C(=N/S(=O)(=O)c2ccccc2)S/C1=C1/C(=O)Nc2ccc([N+](=O)[O-])cc21</smiles>

(Z)-N-((E)-5-(5-nitro-2-oxoindolin-3-ylidene)4-oxothiazolidin-2-ylidene) benzenesulfonamide

(8)

(b)

FIGURE 8: Structures of known inhibitors of bacterial UGM [14].

Each experiment was done in triplicate in a 96-well black bottom plate at final volumes of $25 \mu \mathrm{L}$. Fluorescence anisotropy was measured as indicated above, and the $K_{d}$ values were obtained by fitting the anisotropy data to (2), where $m_{1}$ and $m_{2}$ are the minimum and maximum anisotropy values, respectively; $m_{3}$ is the $K_{d}$ value, and the total concentration of UDP-chromophore is represented by $C_{t}$.

2.7. Determination of the Assay $Z^{\prime}$ Factor. Solutions containing $2 \mu \mathrm{M}$ of AfUGM and $15 \mathrm{nM}$ of chromophore 3 in the absence (negative control) and presence (positive control) of $300 \mu \mathrm{M}$ of UDP were incubated at room temperature for 5 minutes. Each solution was added to octuplicate wells in a 96-well half area black bottom plate with final volumes of $25 \mu \mathrm{L}$. The $Z^{\prime}$ factors were calculated using (3), where $\mu_{-}$ represents the mean anisotropy value of the negative control, and $\mu_{+}$is the mean anisotropy value of the positive control; $\sigma_{-}$represents the standard deviation of the negative control, and $\sigma_{+}$is the standard deviation of the positive control. A $Z^{\prime}$ factor of $0.79 \pm 0.02$ was obtained for chromophore 3 .

$$
Z^{\prime}=1-\frac{3\left(\sigma_{-}+\sigma_{+}\right)}{\mu_{-}-\mu_{+}}
$$

2.8. Optimization of AfUGM Concentration. To determine the optimal concentration of AfUGM in the FP assay, solutions containing $15 \mathrm{nM}$ of chromophore 3 and AfUGM at various concentrations in the absence (negative control) and presence (positive control) of $300 \mu \mathrm{M}$ of UDP were incubated at room temperature for 5 minutes. Each was added to octuplicate wells at a final volume of $25 \mu \mathrm{L}$. FP was analyzed as indicated previously, and $Z^{\prime}$ factors were calculated from (3).

2.9. Competitive Binding Experiments Using FP Inhibition Assay. Solutions $(25 \mu \mathrm{L})$ containing $2 \mu \mathrm{M}$ of $A f \mathrm{UGM}$ and $15 \mathrm{nM}$ of chromophore 3 in $0.05 \mathrm{M}$ sodium phosphate buffer 


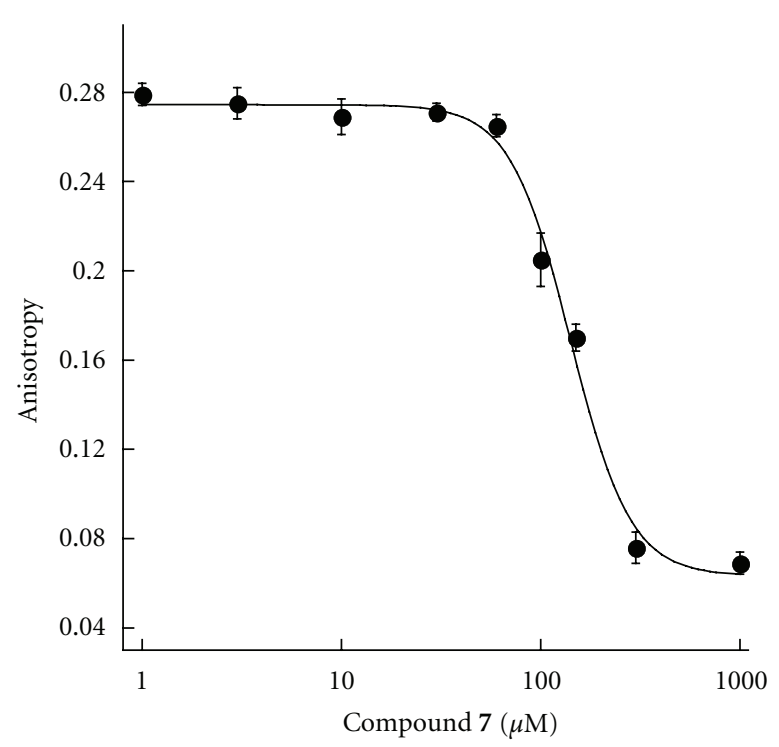

(a)

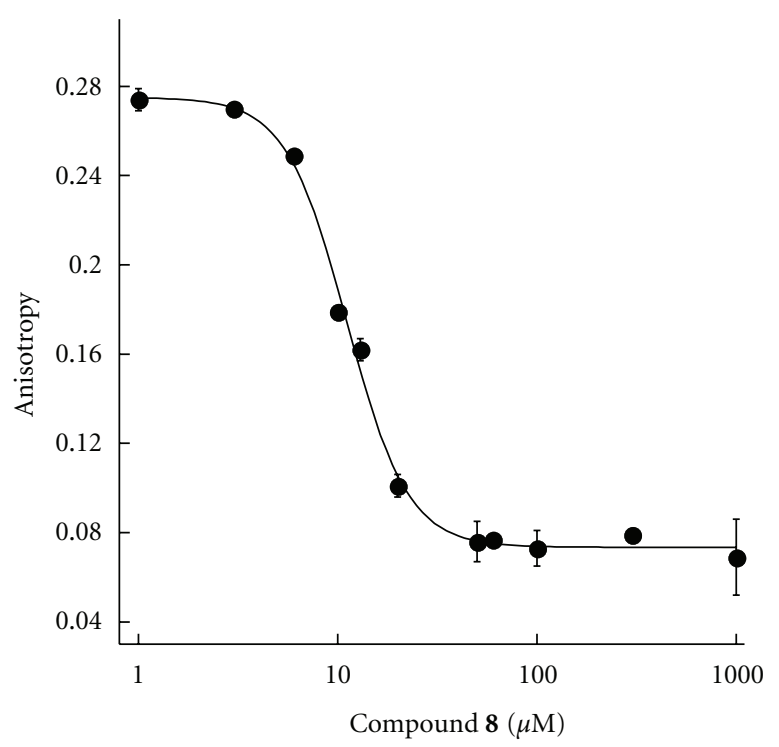

(b)

Figure 9: FP inhibition assay with compounds 7 (a) and 8 (b).

( $\mathrm{pH}$ 7.0) were mixed with various concentrations of UDP, UDP-Galp, 7, or 8 (Figure 8), and the reactions incubated at room temperature for 5 minutes. Each solution was done in triplicate. Anisotropy values were measured and the $\mathrm{IC}_{50}$ values obtained by fitting the data to (4), where $m_{1}$ and $m_{2}$ are the minimum and maximum anisotropy, respectively; $m_{3}$ is the slope, and $m_{4}$ is the $\mathrm{IC}_{50}$. The $K_{d}$ values were obtained using (5), where $K_{i}$ is the binding affinity of chromophore 3 on AfUGM $(2.6 \pm 0.6 \mu \mathrm{M})$, and I is the concentration of the chromophore $(15 \mathrm{nM})$.

$$
\begin{gathered}
y=m_{1}+\frac{\left(m_{2}-m_{1}\right) x^{m_{3}}}{m_{4}^{m_{3}}+x^{m_{3}}} \\
K_{d}=\frac{I C_{50}}{1+\left(I / K_{i}\right)}
\end{gathered}
$$

2.10. AfUGM Activity Assay. The AfUGM activity assay was performed by monitoring the formation of UDP-Galp from UDP-Galf by HPLC. A $20 \mu \mathrm{L}$ reaction containing $20 \mathrm{mM}$ dithiothreitol, $0.5 \mathrm{mM}$ UDP-Galf in $25 \mathrm{mM}$ HEPES, $125 \mathrm{mM}$ $\mathrm{NaCl}$ buffer, pH 7.5 in the absence of 7 or 8 was initiated by the addition of AfUGM at a final concentration of $50 \mathrm{nM}$. After incubation at $37^{\circ} \mathrm{C}$ for $10 \mathrm{~min}$, the reaction was quenched by heat denaturation $\left(95^{\circ} \mathrm{C}\right.$ for $\left.5 \mathrm{~min}\right)$ in a DNA engine thermocycler (BioRad, Hercules, Calif, USA). The same reaction was also performed in the presence of $7(500 \mu \mathrm{M})$ or $8(50 \mu \mathrm{M})$. The suspension was centrifuged and the supernatant was injected onto a CarboPac PA100 (Dionex) anion-exchange column. The sample was eluted isocratically with $75 \mathrm{mM} \mathrm{KH}_{2} \mathrm{PO}_{4}(\mathrm{pH} 4.5)$, and the absorbance at $262 \mathrm{~nm}$ was monitored to identify fractions of substrate and product. The substrate UDP-Gal $f$ was eluted at $36.5 \mathrm{~min}$, and the product UDP-Galp was eluted at $28.3 \mathrm{~min}$. The inhibition of AfUGM activity was indicated by the extent of conversion of UDP-Galf to UDP-Galp.
2.11. Tolerance to DMSO. To determine the tolerance of the assay to DMSO, solutions containing $2 \mu \mathrm{M}$ of $A f \mathrm{UGM}$, $15 \mathrm{nM}$ of chromophore 3 , and DMSO at various concentrations in the absence (negative control) and presence (positive control) of $300 \mu \mathrm{M}$ of UDP were incubated at room temperature for 5 minutes. Fluorescence anisotropy values and $\mathrm{Z}^{\prime}$ factors were calculated as indicated previously.

\section{Results and Discussion}

3.1. Assay Design and Optimization. In this study, we report the development of an FP assay that can be used in a highthroughput format for the identification of inhibitors of AfUGM, which we believe will lead to the development of new therapeutics against A. fumigatus-related diseases. The FP assay was designed as shown in Figure 3. If the UDP fluorescent probe binds to AfUGM and is excited with plane-polarized light, the resulting enzyme-ligand complex tumbles slowly in solution, and thus, the fluorescence emission remains polarized (Figure 3(a)). Otherwise, the emission will be depolarized as the free chromophore will rotate rapidly. The change in the rotational motion between the bound and free chromophore can be used as a signal for detection of the binding of small molecules to the active site of AfUGM because, as the small molecule replaces the bound fluorescent probe, the free probe will rapidly rotate increasing the amount of depolarized fluorescence (Figure 3(b)).

An essential component of an FP assay is a fluorescent probe that specifically binds to the enzyme or protein of interest. To design the fluorescent probe, we reasoned that the incorporation of the UDP moiety into the structure would target binding to the AfUGM active site since it is a major part of the UGM substrate. The fluorophore we first selected was fluorescein because UDP-fluorescein 


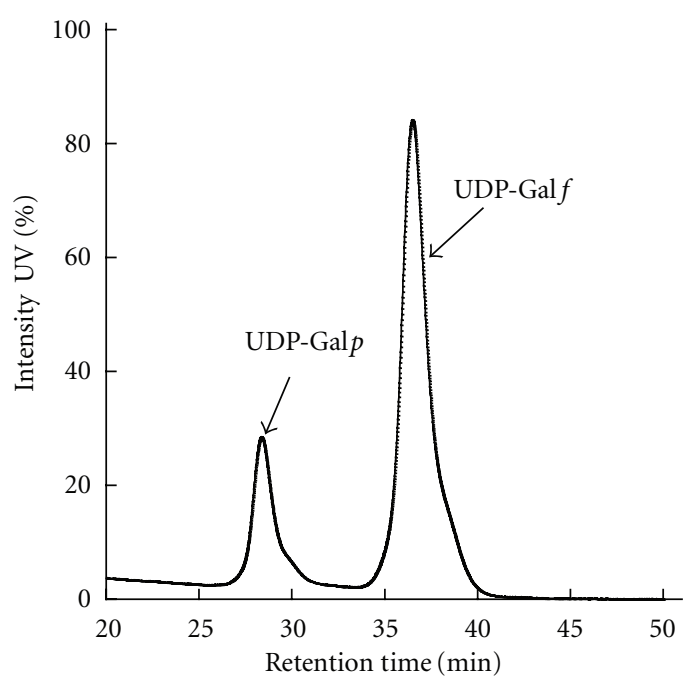

(a)

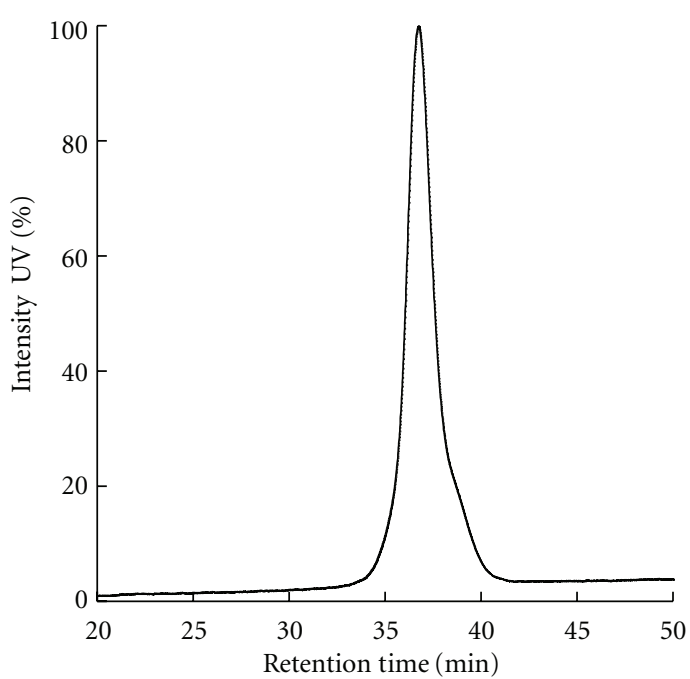

(b)

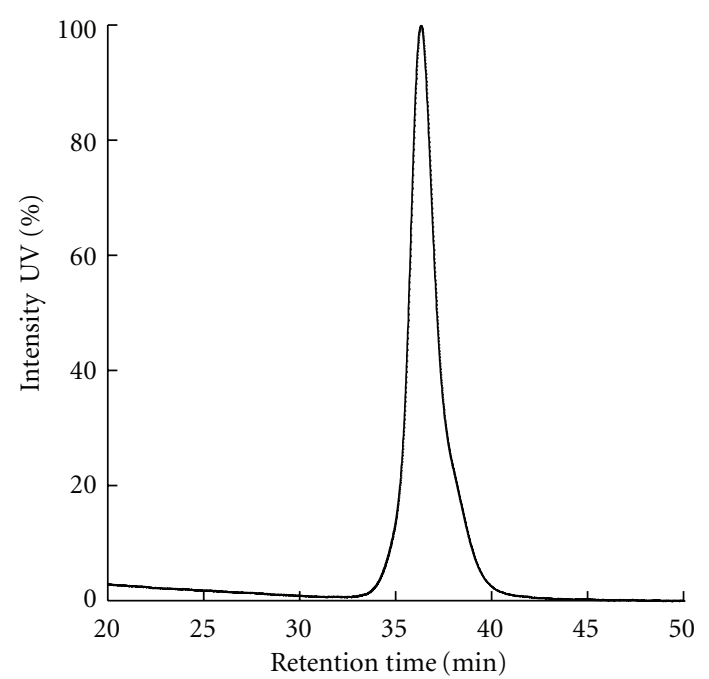

(c)

FIgURE 10: AfUGM activity assay. The HPLC chromatograms at $262 \mathrm{~nm}$ are shown. (a) AfUGM activity in the absence of inhibitor. (b) In the presence of $7(500 \mu \mathrm{M})$. (c) In the presence of $\mathbf{8}(50 \mu \mathrm{M})$.

derivatives have been found to bind to prokaryotic UGMs from Klebsiella pneumoniae and Mycobacterium tuberculosis [15]. To minimize the steric hindrance of fluorescein with Af UGM binding site residues, UDP and fluorescein were connected with alkyl linkers of different lengths, which resulted in two UDP-fluorescein analogs (1 and 2, Figure 2). We also designed a UDP bound to the chromophore, commercially known as TAMRA (Figure 2). This chromophore offers several advantages over fluorescein. First, TAMRA is more resistant to photobleaching compared to fluorescein [16]. Second, the fluorescence emission of TAMRA does not overlap with that of the flavin cofactor in AfUGM. Fluorescein is typically excited at $494 \mathrm{~nm}$ and emits at $520 \mathrm{~nm}$, which significantly overlaps with the absorbance and fluorescence emission of the flavin. In contrast, TAMRA's absorbance and fluorescence maxima is at $546 \mathrm{~nm}$ and 580 $\mathrm{nm}$, respectively [16]. This is significantly different from the flavin absorbance/emission properties and improves signal-to-noise ratio. Finally, in comparison with fluorescein, TAMRA has one extra positive charge, which we believe increases the interaction between TAMRA and flavin and helps improve binding of the probe to AfUGM. Alkyl linkers of different lengths were also included to minimize the steric interaction of TAMRA with the binding site residues, giving two novel UDP-TAMRA analogs ( 3 and $\mathbf{4}$, Figure 2).

In order to increase the signal-to-noise ratio, stable FP values are necessary. Therefore, we varied the concentration of UDP-chromophores to determine the optimal concentration (Figure 4). Stable FP values with minimal standard deviation were obtained at concentrations higher than $15 \mathrm{nM}$. Therefore, we chose the $15 \mathrm{nM}$ UDP-chromophore as the minimal concentration to use for further characterization. cation. Binding of the UDP-chromophore to AfUGM was 


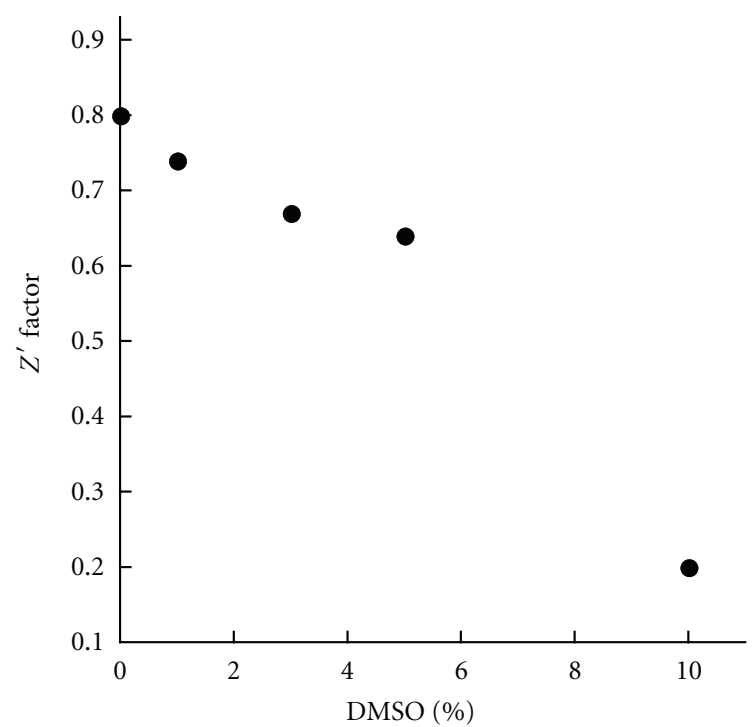

Figure 11: Tolerance to DMSO.

TABLE 1: $K_{d}$ values of UDP-fluorescent probes.

\begin{tabular}{lcc}
\hline Chromophore & $K_{d}$ for AfUGM $(\mu \mathrm{M})$ & $K_{d}$ for $M t \mathrm{UGM}(\mu \mathrm{M})$ \\
\hline $\mathbf{1}$ & $17 \pm 3$ & $>30$ \\
$\mathbf{2}$ & $16 \pm 3$ & $0.10 \pm 0.01$ \\
$\mathbf{3}$ & $2.6 \pm 0.2$ & $0.73 \pm 0.07$ \\
$\mathbf{4}$ & $3.0 \pm 0.7$ & $>30$ \\
\hline
\end{tabular}

determined by varying the concentration of the enzyme at a constant concentration of the UDP-chromophores $(15 \mathrm{nM})$ (Figure 5). Binding assays with the UDP-fluorescein probes (chromophores $\mathbf{1}$ and 2 ) show that these ligands bind weakly to AfUGM, with $K_{d}$ values of $\sim 15 \mu \mathrm{M}$ (Figure 5(a)). This relatively low affinity impedes the utilization of these chromophores for a high-throughput FP binding assay, as it will require high quantities of enzyme. Interestingly, we tested the binding of these chromophores to bacterial UGM from M. tuberculosis, and the $K_{d}$ value of chromophore 2 was $0.10 \pm 0.01 \mu \mathrm{M}$, consistent with previously published values (Table 1) [15]. This tighter binding suggests differences in the active-site architecture between the prokaryotic and A. fumigatus UGM enzymes. This is also consistent with our recent report on binding assays monitoring flavin fluorescence that showed that AfUGM binds UDP-glucose 5 times tighter than K. pneumoniae UGM. Similarly, binding of UDP-Galp to AfUGM was not detected although UDPGalp binds to the bacterial enzyme with a $K_{d}$ value of $220 \mu \mathrm{M}[7,17]$. These differences in ligand binding might originate from the low amino acid identity between the bacterial and eukaryotic UGMs $(<18 \%)$. Furthermore, we have shown that the quaternary structure between these enzymes is not conserved as the bacterial enzymes have been shown to function as homodimers, while AfUGM functions as a homotetramer [7].

With the UDP-TAMRA analogs (chromophores 3 and 4 ), the binding to AfUGM was $\sim 6$ times better than with the UDP-fluorescein analogs, and significant anisotropy change
TABLE 2: $K_{d}$ values of UGM ligands.

\begin{tabular}{lcc}
\hline Ligand & $K_{d}$ for AfUGM $(\mu \mathrm{M})$ & $K_{d}$ for $M t \mathrm{UGM}(\mu \mathrm{M})$ \\
\hline UDP & $9.0 \pm 1.7$ & $15 \pm 2$ \\
UDP-Gal $p$ & $495 \pm 66$ & $563 \pm 75$ \\
7 & $140 \pm 9$ & $21 \pm 1$ \\
$\mathbf{8}$ & $11 \pm 0.4$ & $25 \pm 2$ \\
\hline
\end{tabular}

was measured (Figure 5(b)). Interestingly, the length of the linker had little or no effect on the binding affinities (Table 1), suggesting that with AfUGM the interaction between the chromophore and some components of the active site or perhaps directly with the flavin cofactor play a major role in binding. Compound 3 and $\mathbf{4}$ bound to MtUGM with similar affinities as chromophores $\mathbf{1}$ and $\mathbf{2}$, respectively. In contrast to AfUGM, in the bacterial enzymes, the length of the linker plays a major role in binding with longer linkers increasing the affinity, further demonstrating that the active-site architecture varied among the UGM enzymes. We selected 3 as the FP probe for further characterization of the binding assay.

3.3. Determination of Competitive Binding Using FP Assay. FP competitive inhibition binding assay was conducted to confirm that the FP probes bind to the active site on AfUGM. First, the $\mathrm{Z}^{\prime}$ factor as a function of $A f \mathrm{UGM}$ was determined to establish the proper enzyme concentration to be used in the assay. The $Z^{\prime}$ factor is a statistical parameter that reports on the quality of the assay [18]. As shown in Figure 6, the FP assay exhibits excellent quality at an AfUGM concentration higher than $2 \mu \mathrm{M}$ with a $\mathrm{Z}^{\prime}$ factor above 0.8 . The minimum value $(2 \mu \mathrm{M})$ in this range was selected as the optimal assay concentration.

The $K_{d}$ for UDP was determined using the FP assay by titrating AfUGM with serial dilutions of UDP. A value of $9.0 \pm 1.7 \mu \mathrm{M}$ was obtained, which is in good agreement with the $K_{d}(33 \pm 9 \mu \mathrm{M})$ previously determined by directly monitoring the flavin fluorescence (Figure 7(a)) [7].

UDP-Galp was the second ligand tested in the FP inhibition assay, and a $K_{d}$ value of $495 \pm 66 \mu \mathrm{M}$ was calculated (Figure 7(b)), indicating that UDP-Gal $p$ is a poor ligand for AfUGM, which agrees well with the observation previously reported by Oppenheimer et al. [7].

Recently, a series of prokaryotic UGM inhibitors were identified from chemical libraries by high-throughput screening (HTS) [14]. In our FP assay, we tested two of the best prokaryotic UGM inhibitors, compound 7 and compound 8 (Figure 8). Interestingly, they behaved differently on AfUGM. Compound 7 turned out to be a poor ligand for $A f U G M$ with a $K_{d}$ of $140 \pm 9 \mu \mathrm{M}$ (Figure $9(\mathrm{a})$ ). In contrast, compound $\mathbf{8}$ exhibits much better binding to AfUGM (Figure 9(b)), and its $K_{d}$ was found to be 11 $\pm 0.4 \mu \mathrm{M}$ (Table 2 ). We also tested these two compounds in a secondary assay, directly monitoring the activity of AfUGM to see if these molecules function as inhibitors. The HPLC chromatograms (Figure 10) indicated that both of the compounds inhibit the activity of AfUGM. These results 
confirm that the FP assay identifies ligands that bind to the active site of $A f \mathrm{UGM}$ and that these molecules inhibit the activity of the enzyme in a secondary assay that directly measures product formation.

3.4. FP Assay Quality. The $\mathrm{Z}^{\prime}$ factor value using chromophore 3 was calculated to be $0.79 \pm 0.02$. An assay with a $Z^{\prime}$ factor greater than 0.5 is considered a good assay; therefore, our FP assay is suitable for HTS (Figure 6). We also estimated the tolerance of the FP assay to DMSO by calculating the $Z^{\prime}$ factors at various DMSO concentrations, because a majority of compounds in HTS libraries are dissolved in DMSO. The $Z^{\prime}$ factors were plotted against DMSO concentrations to generate a DMSO calibration curve (Figure 11), and our assay maintains excellent quality with DMSO concentration up to $5 \%(\mathrm{v} / \mathrm{v})$.

\section{Conclusion}

In conclusion, four fluorescently labeled UDP derivatives (1-4) were synthesized and tested for binding to AfUGM. Different from the bacterial UGM, the nature of the chromophore enhanced binding to AfUGM while the length of the linkers did not. UDP-TAMRA analogs ( 3 and $\mathbf{4}$ ) bind to Af UGM with high affinities. Binding of chromophore 3 to the active site of $A f \mathrm{UGM}$ was demonstrated by a competition experiment using UDP and UDP-Galp. Furthermore, binding of known inhibitors of bacterial UGM was tested against AfUGM, and it was found that these compounds bound AfUGM, however, with lower affinities. Inhibition of $A f \mathrm{UGM}$, measuring product formation by HPLC, was demonstrated with compounds 7 and $\mathbf{8}$. A $Z^{\prime}$ factor of 0.79 was calculated, and the assay was shown to exhibit good tolerance to DMSO. We expect that the FP assay described here will allow fast identification of AfUGM inhibitors from chemical libraries. We believe that inhibitors of AfUGM that block the biosynthesis of Galf could lead to novel therapeutics against $A$. fumigatus-related diseases.

\section{Acknowledgments}

This work was supported in part by NIH Grants RO1 GM094469 (P. Sobrado, PI) and RO1 AI082542 (R. Tarleton, PI). M. Oppenheimer was supported by a fellowship from the American Heart Association.

\section{References}

[1] R. J. Trof, A. Beishuizen, Y. J. Debets-Ossenkopp, A. R. J. Girbes, and A. B. J. Groeneveld, "Management of invasive pulmonary aspergillosis in non-neutropenic critically ill patients," Intensive Care Medicine, vol. 33, no. 10, pp. 1694$1703,2007$.

[2] R. L. Kradin and E. J. Mark, "The pathology of pulmonary disorders due to Aspergillus spp," Archives of Pathology and Laboratory Medicine, vol. 132, no. 4, pp. 606-614, 2008.

[3] S. Chong, T. S. Kim, W. J. Koh, E. Y. Cho, and K. Kim, "Invasive pulmonary aspergillosis complicated by pulmonary artery occlusion in an immunocompetent patient," Clinical Radiology, vol. 61, no. 3, pp. 287-290, 2006.

[4] C. Virnig and R. K. Bush, "Allergic bronchopulmonary aspergillosis: a US perspective," Current Opinion in Pulmonary Medicine, vol. 13, no. 1, pp. 67-71, 2007.

[5] G. Chamilos, M. Luna, R. E. Lewis et al., "Invasive fungal infections in patients with hematologic malignancies in a tertiary care cancer center: an autopsy study over a 15-year period (1989-2003)," Haematologica, vol. 91, no. 7, pp. 986989, 2006.

[6] J. P. Latge, "Galactofuranose containing molecules in Aspergillus fumigatus," Medical Mycology, vol. 47, 1, pp. S104-S109, 2009.

[7] M. Oppenheimer, M. B. Poulin, T. L. Lowary, R. F. Helm, and P. Sobrado, "Characterization of recombinant UDPgalactopyranose mutase from Aspergillus fumigatus," Archives of Biochemistry and Biophysics, vol. 502, no. 1, pp. 31-38, 2010.

[8] P. S. Schmalhorst, S. Krappmann, W. Vervecken et al., "Contribution of galactofuranose to the virulence of the opportunistic pathogen Aspergillus fumigatus," Eukaryotic Cell, vol. 7, no. 8, pp. 1268-1277, 2008.

[9] D. Stynen, A. Goris, J. Sarfati, and J. P. Latge, "A new sensitive sandwich enzyme-linked immunosorbent assay to detect galactofuran in patients with invasive Aspergillosis," Journal of Clinical Microbiology, vol. 33, no. 2, pp. 497-500, 1995.

[10] C. Costachel, B. Coddeville, J. P. Latgé, and T. Fontaine, "Glycosylphosphatidylinositol-anchored fungal polysaccharide in Aspergillus fumigatus," Journal of Biological Chemistry, vol. 280, no. 48, pp. 39835-39842, 2005.

[11] C. Simenel, B. Coddeville, M. Delepierre, J. P. Latgé, and T. Fontaine, "Glycosylinositolphosphoceramides in Aspergillus fumigatus," Glycobiology, vol. 18, no. 1, pp. 84-96, 2008.

[12] P. M. Nassau, S. L. Martin, R. E. Brown et al., "Galactofuranose biosynthesis in Escherichia coli K-12: identification and cloning of UDP-galactopyranose mutase," Journal of Bacteriology, vol. 178, no. 4, pp. 1047-1052, 1996.

[13] J. Engel, P. S. Schmalhorst, T. Dörk-Bousset, V. Ferrières, and F. H. Routier, "A single UDP-galactofuranose transporter is required for galactofuranosylation in Aspergillus fumigatus," Journal of Biological Chemistry, vol. 284, no. 49, pp. 3385933868, 2009.

[14] E. E. Carlson, J. F. May, and L. L. Kiessling, "Chemical Probes of UDP-Galactopyranose Mutase," Chemistry and Biology, vol. 13, no. 8, pp. 825-837, 2006.

[15] E. C. Dykhuizen and L. L. Kiessling, "Potent ligands for prokaryotic UDP-galactopyranose mutase that exploit an enzyme subsite," Organic Letters, vol. 11, no. 1, pp. 193-196, 2009.

[16] R. P. Haugland, Handbook of Fluorescent Probes and Research Chemicals, Molecular Probes, Eugene, Ore, USA, 1996.

[17] X. Yao, D. W. Bleile, Y. Yuan et al., "Substrate directs enzyme dynamics by bridging distal sites: UDP-galactopyranose mutase," Proteins, vol. 74, no. 4, pp. 972-979, 2009.

[18] J. H. Zhang, T. D. Y. Chung, and K. R. Oldenburg, "A simple statistical parameter for use in evaluation and validation of high throughput screening assays," Journal of Biomolecular Screening, vol. 4, no. 2, pp. 67-73, 1999. 

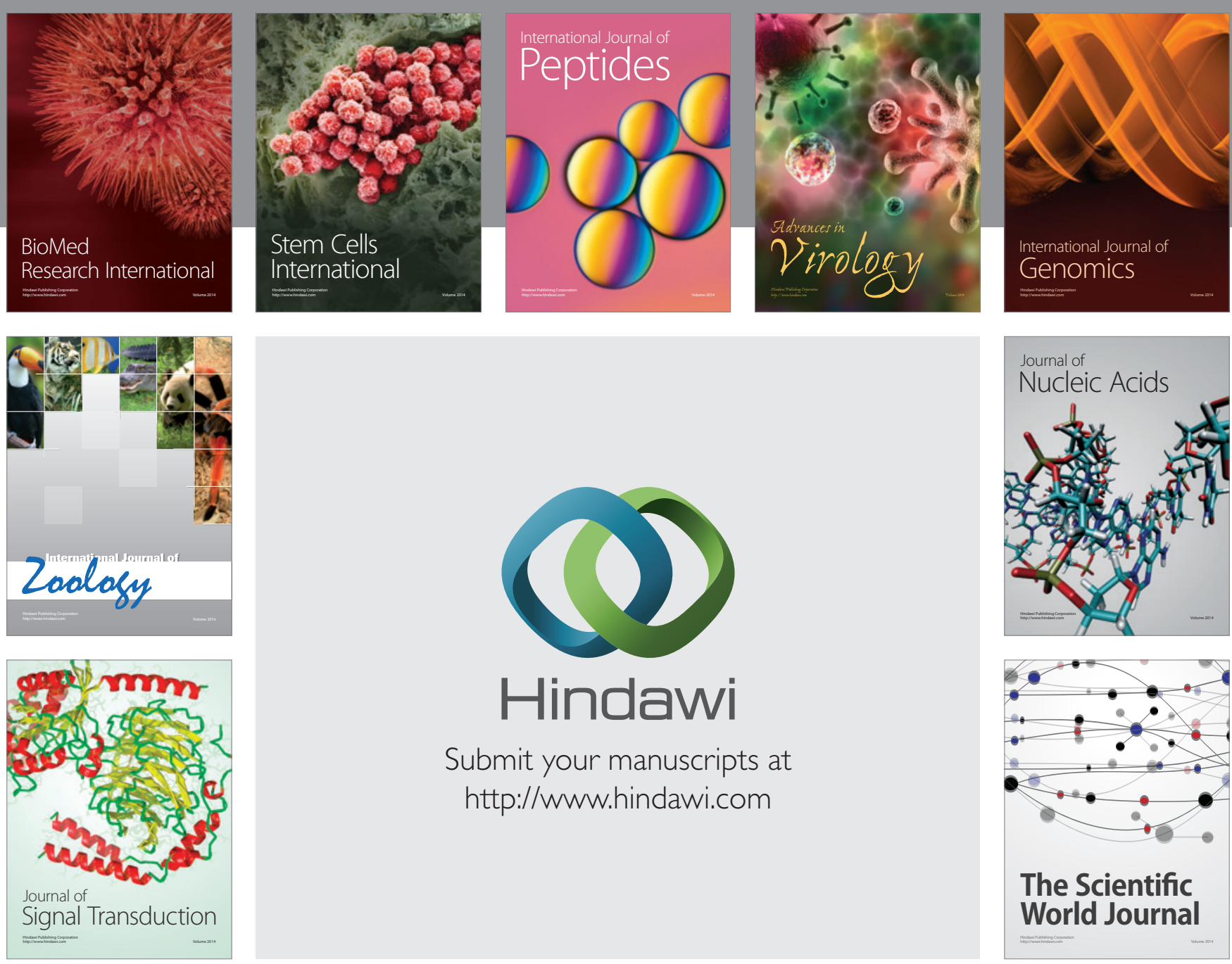

Submit your manuscripts at

http://www.hindawi.com
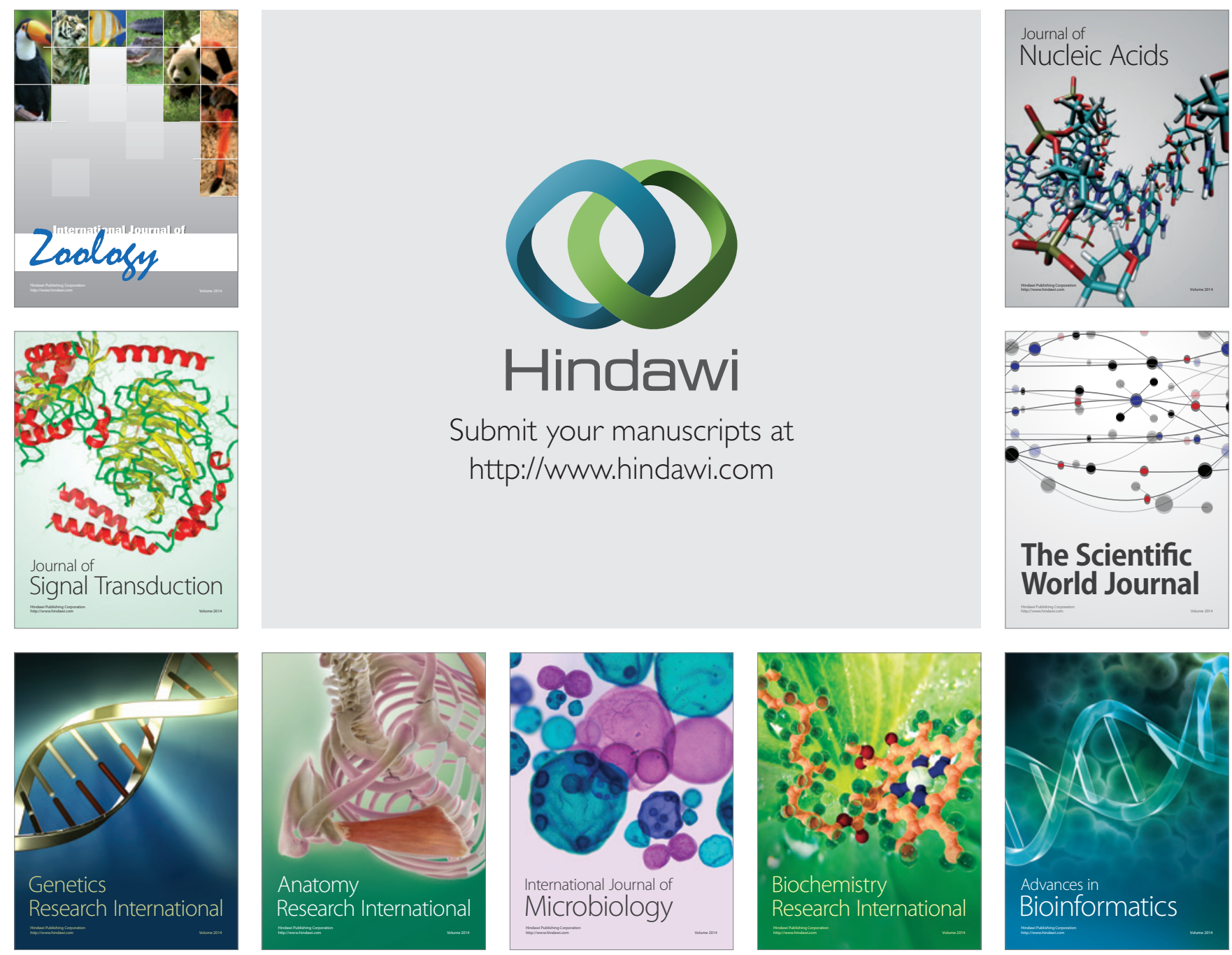

The Scientific World Journal
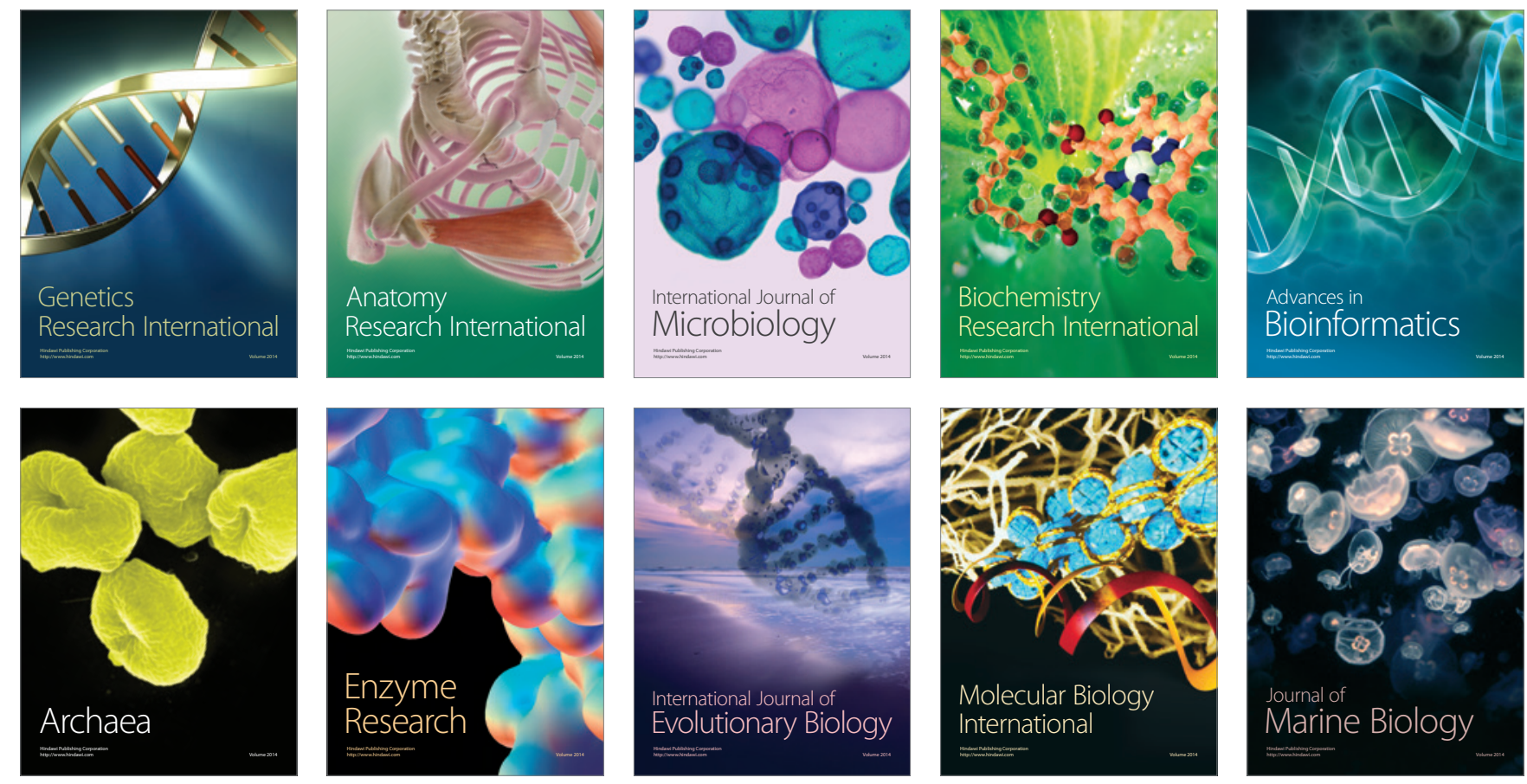